\title{
The best marketing plan of photographing for money deduced by extensible mind mapping
} \author{
Liu, Weitao He \\ Faculty of Software,Guangdong Ocean University,Zhanjiang,China \\ 1037486652@qq.com,fanrui@gdou.edu.cn,972606984@qq.com \\ 452388727@qq.com,1018690570@qq.com,952167400@qq.com \\ liupenghui@outlook.com,1305190319@qq.com
}

Bifeng Guo, Rui Fan ,Chong-wen Huang,Fuyu Ma,Zihao Li, Qiubin Liu,Penghui

\begin{abstract}
With the development of society and economy, there is a new way of marketing research by people's taking photos of the respondents. They can get paid after finishing the survey tasks by taking photos. However, the contradictory problem is that, as for the project leader, the well pay makes him spend too much money while the poor pay causes low task completion rate. The solution to the problem is to put forward a way to find the best marketing plan of the project, which can both meet the demands of marketing research and reduce the budget. By means of Extenics in combination with extensible mind mapping, we find the best marketing plan for it.
\end{abstract}

\section{Introduction}

Photographing for money is a kind of self-service model of Internet. Users can apply for VIP after downloading the cell phone application. The VIP of it can get the research task they want. The tasks are usually photographing some information like shelves of goods that can't be searched from the Internet. The VIP of the application can get paid after finishing the task of photographing. This kind of way of marketing research not only provides companies with merchandise check and useful information but also it takes less time compared with conventional marketing research. Besides, it guarantees the authenticity of the data.

As for the research manager, he or she should make the price of each task according to different situations. However, there is a deadly problem in the promising way of marketing research. That is, if the price is high, the project manager may spend much money to complete the marketing research, in contrast, the project won't be finished.

In this case, finding the best price of each task becomes the key question of it.

Photographing for money is a contradictory problem and it is the best way to solve the contradictory problem by means of Extenics [1]. The discipline provides us with formalized model to explore the possibility of objects and methods of extensive innovation [2], which is used to address problems in various fields. Our team devoted ourselves to develop computer-aided software based on Extenics. We have done some research about innovative software architecture and developed an innovative mobile software. We developed an Extensive mobile software [3], did some research on web service-based Extensive system 
[4], worked for modeling Extenics innovation software [5] and explored a method for self-adapted software[6]. The way of mind mapping [7] was put forward long time ago and some developed software based on mind mapping can intuitively activate our divergent thinking [8], enlarging the mindscape of us. However, the software has no convergence mechanism and it can't direct our thinking to success. Extenics offers us both way and procedure of innovative thinking. Besides, it provides a way to evaluate superority values for each step of innovative thinking in combination with quantitative and qualitative mathematical model, creating reference for next-step thinking direction. Nevertheless, Extenics is a mathematical way [9] after all. It can't clearly reflect the deduced thinking of people. Therefore, it is a new innovative way, namely, to solve problems based on mind mapping in combination with Extensive procedures and methods so that people can deduce problems intuitively and regularly, hence the thinking deductive architecture of Extenics with mind mapping (see Figure 1). From Figure1 we can see there is an original problem breaks down into a subproblem which can be the kernel problem if it can't break down. As for the kernel problem, we can make a modeling setting its conditional element, goal element and dependent function. Each of them can change itself to another and finally change it into a best one. Then we make Extensive transformation and superiority evaluation. This is the whole procedure of Extensive solution printed on the mind mapping. Not only can it reflects our thinking intuitively but it leads us to a right thinking to solve problems.

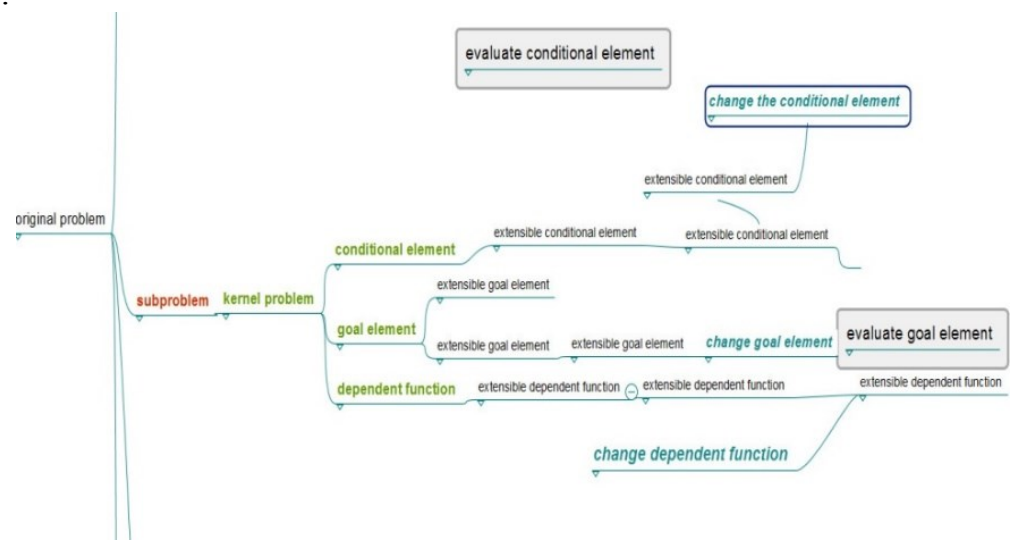

Figure1 Extenics Mind Mapping

\section{Procedures of solving the problem}

\subsection{Data preprocessing}

To find a completed project for analysis, we found the data from a Chinese mathematical modeling contest. The project consists of 835 sets of data including each set of task number, task latitude, task longitude, price and its completion. We processed the data with Excel trying to look for the relationship among each task's geographical situation, price and completion.

By comparing Figure 2 with map of Guangdong Province, China, we find that most prices of these tasks are between 60 and 70 and they are located in traffic developed places. Our analysis to related papers proved that the train station of each city is the center of the city. Then we select 5 positions of the relevant train stations in order to explore which district each task belongs to i.e., Guangzhou Station, Foshan Station, Dongguan Station, Shenzhen Station and Huizhou Station. To find which city these tasks belong to, we 
calculate the distance between each task position to the 4 stations, judging them by the shortest distance. Then we analyze the task amount, completed task and completion rate of each district. The table (Table 1) is shown below.

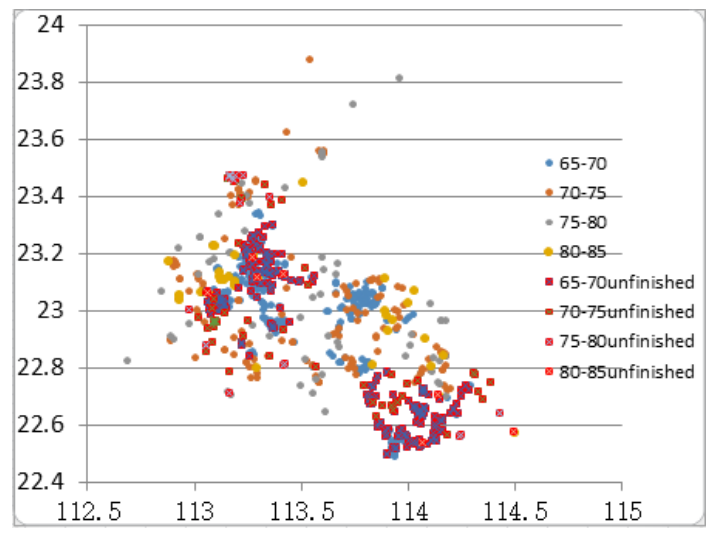

Figure2 Task Distribution

Table 1 District-completion Statistics

\begin{tabular}{|l|l|l|l|}
\hline District & Total tasks & Completed tasks & $\begin{array}{l}\text { Completion } \\
\text { Rate }\end{array}$ \\
\hline All & 835 & 522 & $62.51 \%$ \\
\hline Guangzhou & 313 & 191 & $61.02 \%$ \\
\hline Shenzhen & 188 & 64 & $34.04 \%$ \\
\hline Foshan & 161 & 101 & $62.73 \%$ \\
\hline Dongguan & 172 & 165 & $95.93 \%$ \\
\hline Huizhou & 1 & 1 & $100 \%$ \\
\hline
\end{tabular}

We exclude the data in Position Huizhou for there is only a set of data. Next we analyze the data to find out the factors influencing the completion rate. By consulting some papers, we eventually ensure that the economic development level of each district greatly influences the completion rate. Consequently, we look up the data of the economy in these districts. They are shown below.

Table 2 District Economy Level

\begin{tabular}{|l|l|}
\hline District & $\begin{array}{l}\text { Annual GDP per } \\
\text { capita }\end{array}$ \\
\hline Guangzhou & 21868.09 \\
\hline Shenzhen & 25789.98 \\
\hline Foshan & 17485.11 \\
\hline Dongguan & 12453.30 \\
\hline
\end{tabular}

For the sake of convenient calculation, we define Variable $\mathrm{E}$ to describe the economy level. According to the data above, $\mathrm{Egz}=22.0, \mathrm{Esz}=26.0, \mathrm{Efs}=17.5, \mathrm{Edg}=12.5$. Also, we define another variable Local Value Rate to describe whether each task is worth completing, which is defined as Formula 1. 


$$
\text { LocalValueRate }=\frac{\text { Marked Pr ice }}{E}
$$

We calculate the Local Value Rate and compare it with completion rate to explore the relationship between them. Table 3 below shows the data.

Table 3 Value Rate and Completion

\begin{tabular}{|l|l|}
\hline Local Value Rate & Task Completion \\
\hline $2.9-3.2$ & 0.4892 \\
\hline $3.2-3.5$ & 0.6029 \\
\hline $3.5-3.8$ & 0.4285 \\
\hline $3.8-4.1$ & 0.4861 \\
\hline $4.1-4.4$ & 0.6923 \\
\hline $4.4-4.7$ & nil \\
\hline $4.7-5.0$ & 0.9333 \\
\hline $5.0-5.3$ & 0.9091 \\
\hline $5.3-5.6$ & 0.9259 \\
\hline $5.6-5.9$ & 0.9811 \\
\hline $5.9-6.2$ & 0.9429 \\
\hline $6.2-6.5$ & 0.9545 \\
\hline $6.5-6.8$ & 1 \\
\hline $6.8-7.1$ & 1 \\
\hline
\end{tabular}

We analyze the data above with software called SPSS, reflecting the relevance of Local Value Rate and Task Completion is $85.8 \%$. So we draw a conclusion that local economy level also influences the completion besides the price.

\subsection{The advantages to using freeplane}

We solve the problem by deducing a tree in the software called Freeplane[10] in combination with Extenics.

The software Freeplane provides us with a visible mind mapping, from which we can draw figures and profiles according man's thoughts. We can draw a part of mapping whenever we think of the problem and it can carve human's procedure of addressing problem in the software shown as a mapping that is easy to understand. The software fits mind for Extenics innovation well. Mind mapping without Extenics innovation can't control minds' thinking, causing the mess of human's innovative direction. Consequently, we solve the problem by using Freeplane in combination with Extenics means.

\subsection{Problem modeling}

In this problem, what we are concerned about is whether we can increase the completion without spending more money. There is no doubt that without taking any action, the completion is a fixed value. The task completion now is $62.5 \%$ and we should make it greater than $62.5 \%$. Through analyzing, there are 2 kernel problems to be found. They are finding out other marketing plans and changing the local economy level.

According to the Extensive innovation first we set up the goal element and conditional element, defining a discrete dependent function in the mind mapping. The mind mapping is shown in Figure3. 
After the model set, we manage to think of the plans where there are more positive elements in order to increase the dependent function value by means of Extensive innovation. As for another kernel problem changing the local economy level, it seems that it is not our ability to change the economy level of each district and it is a ridiculous thought. So we don't refer to it in the following.

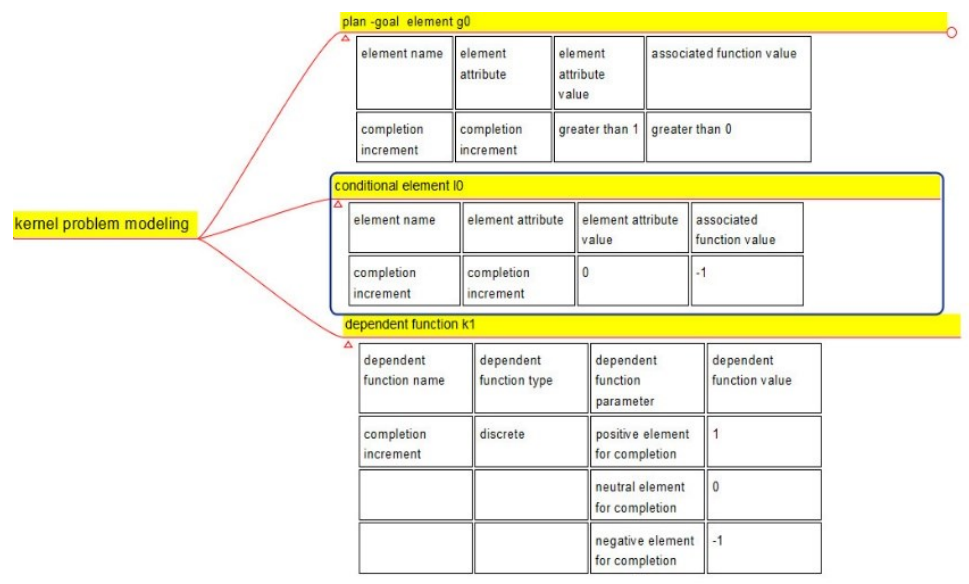

Figure3 Problem Modeling

\subsection{Extensible transformation}

Heading for the goal element, we find out three marketing plans that can meet the requirement. They are distance-changed plan, price-accumulated plan and package plan. We think of 3 elements aimed at the 3 marketing plans including distance factor, difficulty factor and human factor. The details of the 3 marketing plans are shown below.

Distance-changed plan: First the manager hands out a part of tasks close to the center of a district where the traffic is developed. After most of the handed-out tasks are completed, the manager hands out some tasks a little farther from the center of a district to increase the complement. As for the plan, at the beginning of the project without changing the price, more people will be willing to finish the tasks. Then after the next tasks are handed out, people would like to go to the place to get more payment and they can complete more tasks without changing places, which is positive to distance factor. The difficulty of the task is fixed in the plan, which is neutral difficulty factor. As for the task catchers, they prefer this plan for the reason that they can get more earnings in a trip, which is positive to human factor. Consequently, the element attribute value is 2 .

Price-accumulated plan: At a certain time, task catchers get less payment of each task when completing fewer tasks. As they completed more tasks, each payment of each task increases according to their completion quantity. The plan doesn't make a constraint of distance to them compared with the original plan, which is neutral to distance factor. The difficulty of the plan is fixed too, which is neutral to difficulty factor. As for the task catchers who catch fewer tasks in a certain time, it is disadvantageous for them. However, it is beneficial for those who catch more tasks, which is neutral to human factor. The element attribute value is 0 .

Package plan: The manager makes some of the closed tasks cascade so that many catchers will not argue for the same task and they get paid after completing a cascade of tasks. This is neutral to distance factor. The tasks that are easier to be completed will be completed more quickly. However, the harder's one's completion may decrease causing 
other easier tasks unfinished in the same cascade, which is negative to difficulty factor. The thought of package is a comparison to salary system, people prefer annual salary system than monthly salary system, which is positive to human factor. Consequently the dependent attribute value is 0 .

We place the innovative procedure to the mind mapping, showing the mind of human while having an innovative thought.

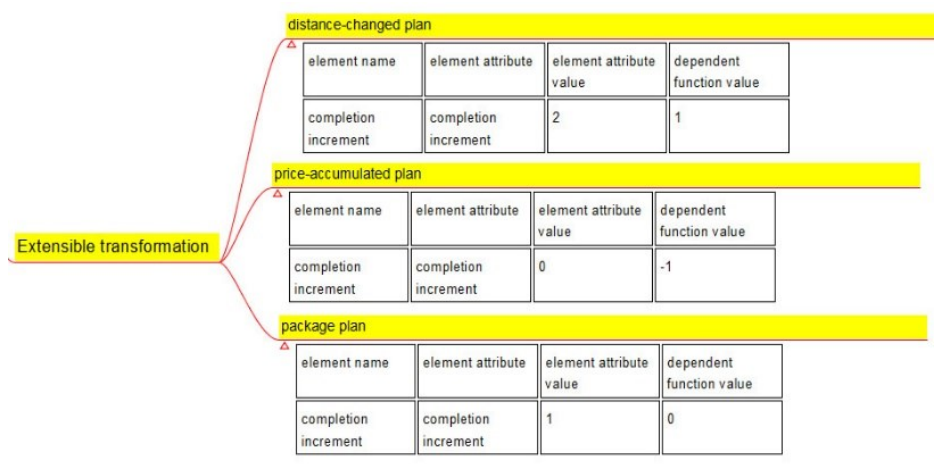

Figure4 Extensible Transformation

\subsection{Superiority evaluation}

From 3 marketing plans above, we select a best marketing plan for the problem for its attribute dependent function value is 1.0 and it is greater than the other two, reflecting that distance-changed plan is the best mathematical model among the three plans and it is more likely to solve the contradictory problem in this case. Consequently, we select it as the best marketing plan. The whole procedure of the innovative mind in combination with Extenics is shown in Figure5.

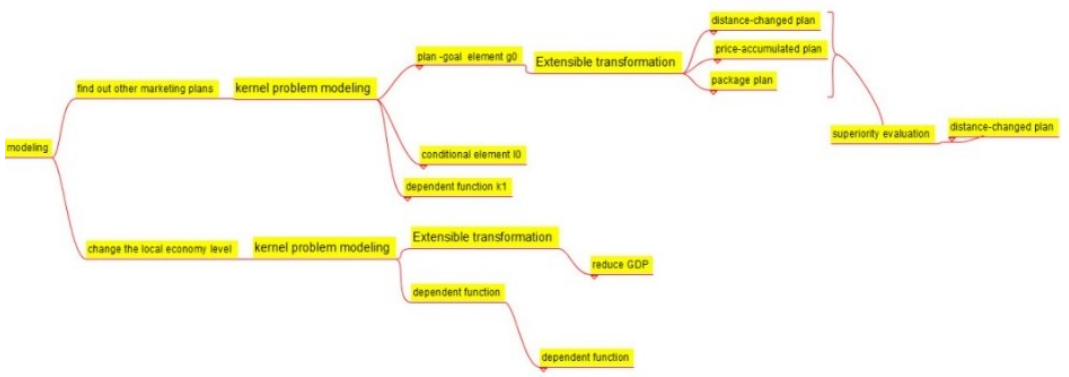

Figure 5. Whole Procedure of Innovation Mind

\section{Conclusion}

In order to make the marketing research effectively, the idea of photographing for money was put forward. However, the problem is that well pay makes the company spend too much money while the poor pay causes low task completion rate. We create a new way to solve the problem by the methods of Extenics in combination with mind mapping, and it solves the contradictory problem to some extent. We draw a conclusion that distance-changed plan is the best marketing plan in this issue. The manager can start a marketing research in this way and improve the plan in practice. Besides, the marketing 
plan can also be used in the issue of Taxi Problem and Dining Problem. What we are going to research is that developing a new software in combination with both Extenics and mind mapping so that we can solve problems in the correct direction and make the mind mapping more intuitively.

\section{Acknowledgements.}

The research is supported by Guangdong Provincial Science and Technology Project (2014A040402010) and Guangdong Province Innovation and Entrepreneurship Training Program for College Students (201710566036).

\section{References}

1. Wen C, Yang C. Basic theory and methodology on Extenics [J]. Chinese Journal, 2013, 58(13):1190.

2. $\mathrm{Li} \mathrm{X}, \mathrm{Li} \mathrm{L}, \mathrm{Chen} \mathrm{Z}$. toward Extenics-Based Innovation Model on Intelligent Knowledge Management [J]. Annals of Data Science, 2014, 1(1):127-148.Association A M. Journal of Marketing Research [J]. Journal of Marketing Research, 2004, 17(6):900-909.

3. Yan S, Fan R, Chen Y, et al. Developing Mobile Software for Extenics Innovation [J]. 2016.Cai W, Yang C Y, Bin H E. Several Problems on the Research of Extenics [J]. Journal of Guangdong University of Technology, 2001.

4. Yan S, Fan R, Chen Y, et al. Research on Web services-based Extenics Aided Innovation System [J]. Procedia Computer Science, 2017, 107(C):103-110.

5. Rui Fan. Modelling Extenics Innovation Software by Intelligent Service Components. The open Cybernetics and Systemics Journal, Volume 8, 2014:1-7.

6. FAN Rui, PENG Yinqiao, CHEN Yuefeng,etc.A method for self-adaptive software formal modeling by Extenics. CAAI Transactions on Intelligent Systems, 2015, 10(6): 901-911.

7. Helen Kershaw. Mind mapping [J]. Bereavement Care, 1998, 17(3):44-44.

8. Mccrae R R. Creativity, divergent thinking, and openness to experience [J]. Journal of Personality \& Social Psychology, 1987, 52(6):1258-1265.

9. $\mathrm{Li} \mathrm{X}, \mathrm{Li} \mathrm{L}, \mathrm{Chen} \mathrm{Z}$. toward Extenics-Based Innovation Model on Intelligent Knowledge Management [J]. Annals of Data Science, 2014, 1(1):127-148.

10. Surhone L M, Tennoe M T, Henssonow S F. Freeplane [J]. Milwaukee Journal Sentinel, 2010, 65(1):93-95. 